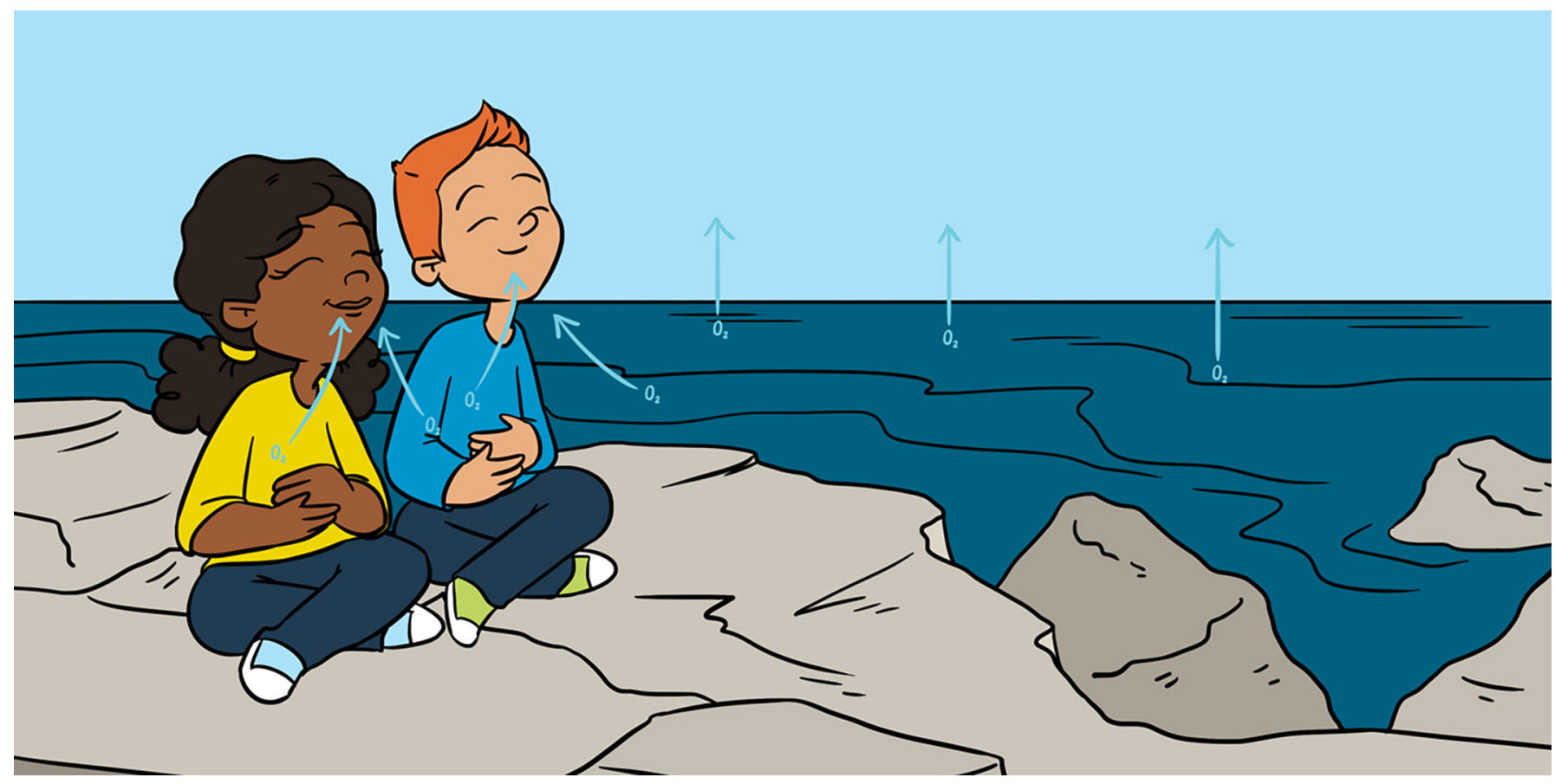

\title{
DO YOU LIKE TO BREATHE? DIATOMS CAN HELP YOU WITH THAT!
}

\author{
Leena Virta ${ }^{1,2^{*}}$ and Alf Norkko ${ }^{2,3}$ \\ ${ }^{1}$ Department of Geosciences and Geography, University of Helsinki, Helsinki, Finland \\ ${ }^{2}$ Tvärminne Zoological Station, University of Helsinki, Hanko, Finland \\ ${ }^{3}$ Baltic Sea Centre, Stockholm University, Stockholm, Sweden
}

\section{YOUNG REVIEWERS:}

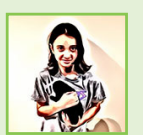

FRESIA

AGE: 11

ROHAN

AGE: 10
Have you ever thought about why we never run out of oxygen even though there are so many of us breathing constantly? The answer is that there are plants and algae that produce new oxygen at the same rate as we use it. Surprisingly, the most important oxygen producers are not large trees but tiny algae that live in the water, and one of the most important groups among them are the diatoms. Because the diversity of life is now decreasing all over the world, we wanted to find out whether having many different species of diatoms is important for oxygen production, or if just a few species would be enough. Our results showed that species-rich communities of diatoms were more effective in providing oxygen. This means that we should work to avoid destroying our oceans, lakes, and rivers to make sure that we have healthy diatom communities also in the future. 
Figure 1

Bubbles on the seafloor, produced by diatoms and other tiny organisms living in the water. These organisms make sure that we have enough oxygen to breathe.

\section{PHOTOSYNTHESIS}

A process where green plants, algae, and some other organisms use light energy to convert water, carbon dioxide, and minerals into oxygen and energy.

\section{CHLOROPHYLL}

A green pigment that enables photosynthesis.

\section{DIATOM}

A microscopic alga that has silica-containing cell walls.

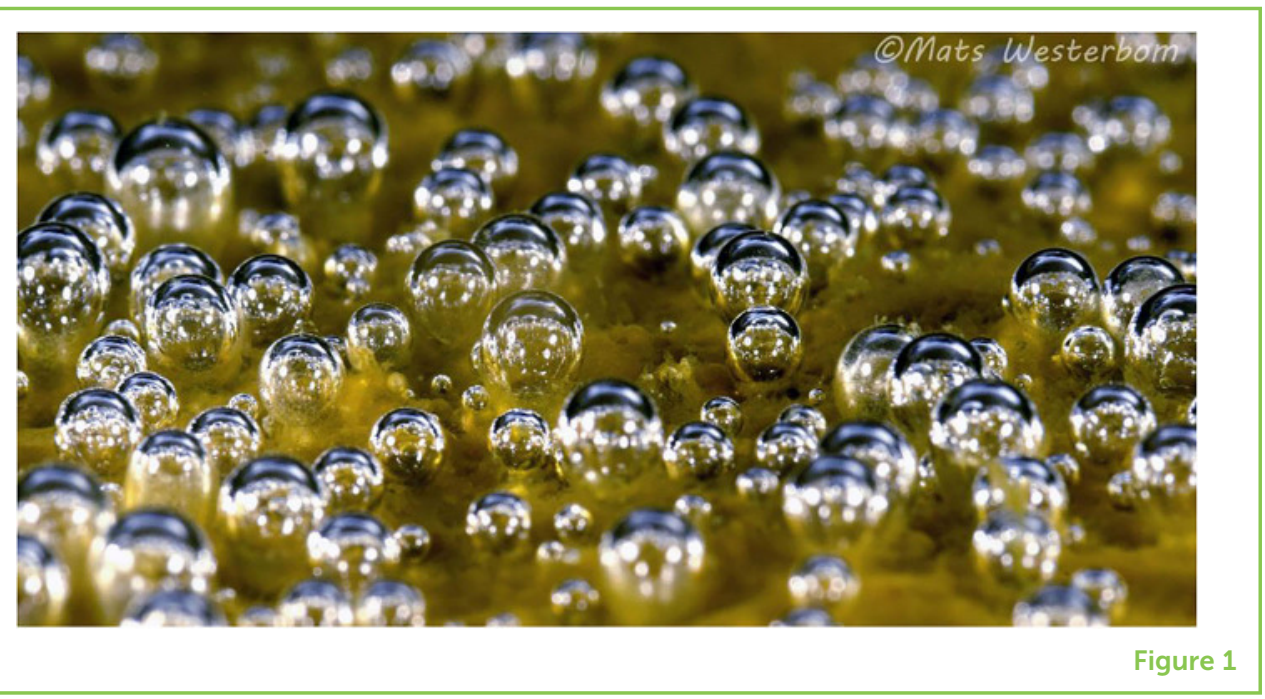

\section{WHO SHOULD WE THANK FOR THE OXYGEN WE BREATHE?}

How long can you hold your breath? Not very long! Humans-you and I-need up to 2,000 I of oxygen every day. You probably know that all this oxygen in the world is produced by organisms, such as plants and algae that perform photosynthesis. In other words, they take carbon dioxide, water, and sun-light and use chlorophyll, which is a green-colored material inside them, to produce energy and oxygen. They keep the energy for themselves, but release the oxygen into the environment for all of us to breathe. Rainforests, with their large trees, have often been thought of as being "the lungs of the Earth," giving us most of the oxygen we need. However, guess what?! Actually, the large rainforest trees are outmatched by a tiny opponent! It is primarily the microscopic organisms living in water that we have to thank for the oxygen that we breathe (Figure 1). While there are many different kinds of these important little creatures in the world's waters, we will concentrate on one specific group, called diatoms.

\section{DIATOMS-AQUATIC BEAUTY QUEENS}

Diatoms are extremely small algae, $<0.2 \mathrm{~mm}$ in size, which means that it takes more than fifty diatoms to equal the length of a mosquito. It also means that you need a microscope to see them. Looking at diatoms through a microscope is worthwhile, because they are incredibly beautiful and diversified-there are over 20,000 diatom species in the world and every species looks different (Figure 2). However, there is one specific feature that unites all diatoms and makes them unique among all the tiny aquatic inhabitants-a cell wall made of silica. Silica is what gave Silicon Valley its name since many electronic computer parts are held together by silica. Silica is also an element used by many plants and algae to strengthen their bodies. The silica-containing cell walls of diatoms are so hard that the diatoms can 
Figure 2

Diatoms as seen through a microscope. These are three of the several hundred diatom species that we found in the Baltic Sea in northern Europe. Although diatoms are tiny, each species looks different because of the unique features of the silica-containing cell wall. Diatom species only have Latin names.

\section{BIODIVERSITY}

The entire variety of life on Earth, including every living thing.

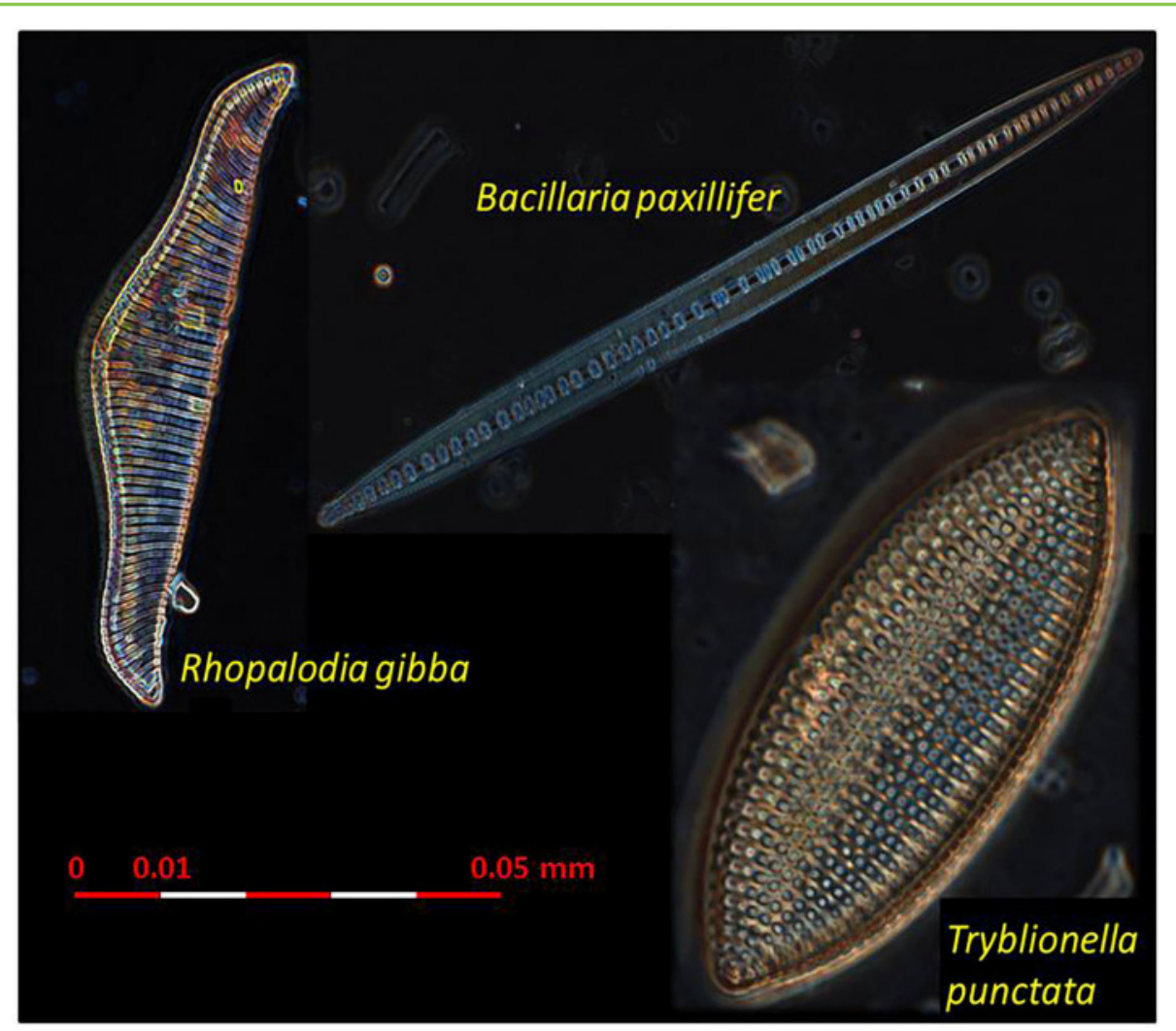

Figure 2

remain buried in the sediment at the bottom of the ocean for millions of years and still remain in such good condition that researchers can identify the exact species! Diatoms live in all kinds of waters-oceans, seas, lakes, rivers, and even in the extreme conditions of hot springs or Antarctic ice. In all these environments, diatoms are the favorite food for many small animals, such as snails and mussels, and they help entire ecosystems to function effectively.

There is still much that researchers do not know about diatoms because these organisms are so small that studying them is difficult. Researchers know that the world's biodiversity, which is the total number of species or habitats present on Earth, is very important for the health of our planet-and us humans. However, what about the diversity of diatoms? Do we need all the 20,000 diatom species, or would it be enough to have just a few?

\section{THE BALTIC SEA: THE HIDDEN TREASURE OF NORTHERN EUROPE}

To investigate the question of whether a high diversity of diatom species is needed for the healthy functioning of the Earth, we set out to take a closer look at the bottom-dwelling diatoms in the Baltic Sea, which is in northern Europe. Unless you live in the area, the Baltic Sea 


\section{BRACKISH}

Water that has more salinity than freshwater but not as much salinity as seawater. may be unfamiliar to you, because it is not famous for having corals or colorful fish. However, the Baltic Sea has many characteristics that make it special and fascinating. First of all, species in the Baltic Sea must cope with a mix of salty water and fresh-water, called brackish water. Because the Baltic Sea is connected to the ocean only by a narrow strait, the salinity of the Baltic Sea is lower than that of the oceans but higher than that of freshwater lakes and rivers. Therefore, the species living there have had to find ways to survive in these strange conditions. Second, the ice age, as the Ice Age movies show, formed an amazing up to $3 \mathrm{~km}$ thick glacier cover in the northern European latitudes where the Baltic Sea is nowadays located. Thus, the Baltic Sea was formed, and the current species were able to live there, only after the glacier cover melted about 11,000 years ago. Although that sounds like a very long time for a human being, it is a rather short time for an ecosystem, and the Baltic Sea and its species are still evolving. This means that new environments and new species are continuously being formed there.

\section{TEAMWORK MAKES THE DREAM WORK!}

To take a closer look at how diatoms affect oxygen production, we used diving gear to dive to the bottom of the Baltic Sea, in shallow bays where there is plenty of light for the diatoms and other organisms to grow on the sediment surface. We collected samples using tubes that can be pushed into the soft sediment. Back on the surface, we analyzed the diversity of diatoms in the samples by using a microscope to identify all the diatom species present. We also measured the amount of chlorophyll in each sample. Because chlorophyll is important for photosynthesis, measuring the amount of chlorophyll can tell us how much oxygen the diatoms can produce. Finally, we compared the diversity of diatoms to the amount of chlorophyll in each sample, to see whether the diversity of diatoms was related to the amount of oxygen they could produce.

We found interesting results. The diversity of diatoms really seemed to matter (Figure 3)! When there were only a few species of diatoms in the community, the amount of chlorophyll was uneven, sometimes low and sometimes high, maybe because there were sometimes other organisms present that helped to boost the chlorophyll or because there were some specific diatom species that had a lot of chlorophyll inside them. However, when several different species of diatoms were present in the community, there was always plenty of chlorophyll, and the communities were able to produce a lot of oxygen. Thus, a higher diversity of diatoms ensured that the ecosystem at the bottom of the sea was able to function well and produce the oxygen that humans need to breathe. It seems that "teamwork makes the dream work" is a phrase that also applies to diatoms. 
Figure 3

In our study, we found that the diversity of diatoms formed the lower limit to the amount of chlorophyll. This means that if there were only a few species of diatoms in the community, the amount of chlorophyll present and the amount of oxygen that the community could produce was uneven, but if there were many different species of diatoms in the community, the amount of chlorophyll and the oxygen production were increased and more stable.

\section{Diatom diversity matters!}

We diatoms produce oxygen for you! We come in many different species. How many diatom species can you see below? Look at our colors and shapes.
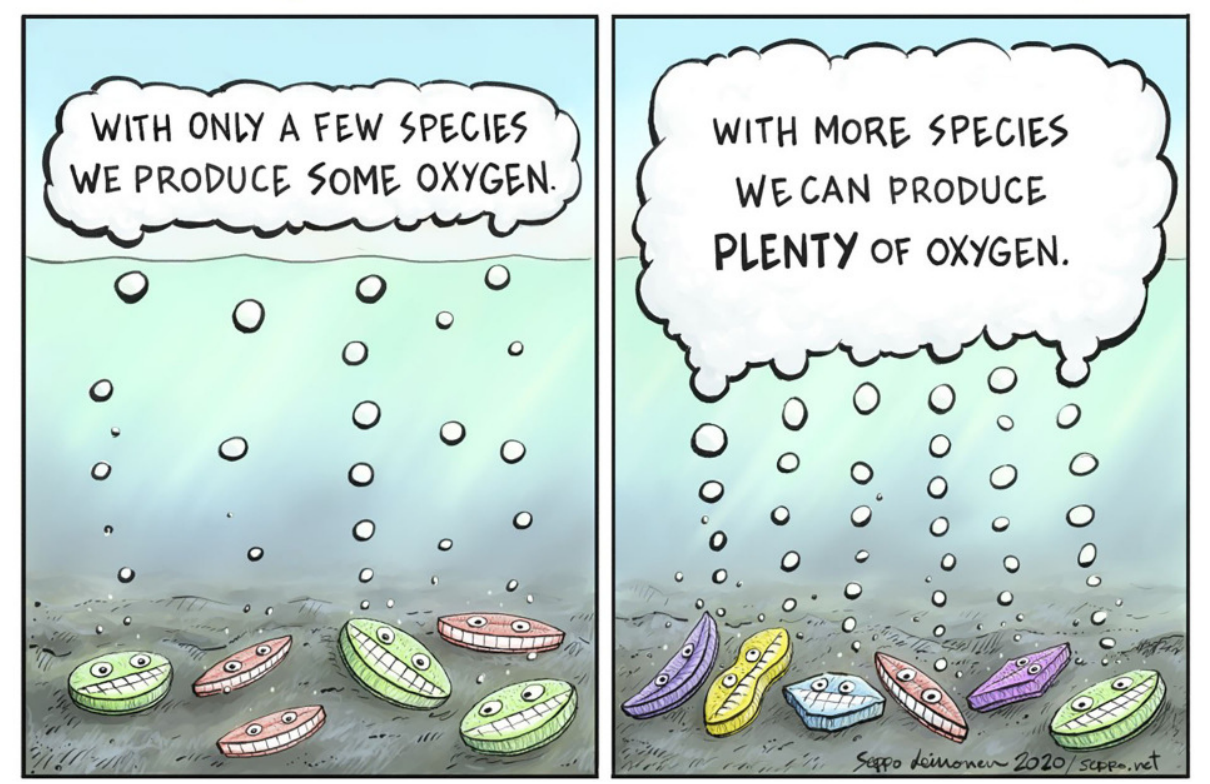

Figure 3

\section{HOW CAN WE HELP DIATOMS TO THRIVE?}

As you probably are aware, the biodiversity of the whole world is at risk at the moment, because we humans are using too much space and too many of the planet's resources, making it difficult for other organisms to survive. While we usually tend to worry more about the cute and fluffy animals, in this study we showed that we should be just as concerned about the diversity of the tiny diatoms that help us to keep breathing. But how can we protect the diatoms? They are so small that protecting specific species is not feasible, but we can protect the diversity of entire diatom communities by making choices that reduce climate change and that keep the environment as healthy as possible. Many of these actions are the responsibility of adults, but you can also help. For example, you can try going to school by bike instead of a car, or you can do your best to keep the nature around you clean and healthy. If everyone does their part, we can preserve the world's biodiversity and keep the environment healthy for humans, diatoms, and all other species.

\section{ORIGINAL SOURCE ARTICLE}

Virta, L., Gammal, J., Järnström, M., Bernard, G., Soininen, J., Norkko, J., et al. 2019. The diversity of benthic diatoms affects 
ecosystem productivity in heterogeneous coastal environments. Ecology 100:e02765. doi: 10.1002/ecy.2765

SUBMITTED: 20 April 2020; ACCEPTED: 16 February 2021;

PUBLISHED ONLINE: 04 March 2021.

EDITED BY: Emily King, Xiamen University, China

CITATION: Virta L and Norkko A (2021) Do You Like to Breathe? Diatoms Can Help You With That! Front. Young Minds 9:553748. doi: 10.3389/frym.2021.553748

CONFLICT OF INTEREST: The authors declare that the research was conducted in the absence of any commercial or financial relationships that could be construed as a potential conflict of interest.

COPYRIGHT (c) 2021 Virta and Norkko. This is an open-access article distributed under the terms of the Creative Commons Attribution License (CC BY). The use, distribution or reproduction in other forums is permitted, provided the original author(s) and the copyright owner(s) are credited and that the original publication in this journal is cited, in accordance with accepted academic practice. No use, distribution or reproduction is permitted which does not comply with these terms.

\section{YOUNG REVIEWERS}

\section{FRESIA, AGE: 11}

I love science and math, but I am not a fan of history and geography. My big passion is animals. I have a snake named Sacha Jr. and a rabbit named Luna, and I love to raise silkworms and search for lizards and other animals in the wild. I am also learning to ride horses and I love using creativity to make crafts.

\section{ROHAN, AGE: 10}

I am interested in airplanes, engineering, Richard Trevithick, Isambard Kingdom Brunel, dinosaurs, mixoplankton, and other mixotrophs, the deep sea, Lego. I enjoy reading science fiction (like 20,000 Leagues under the Sea), fantasy, and non-fiction. I like kayaking, cycling, and hockey.

\section{AUTHORS}

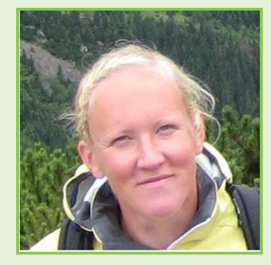

\section{LEENA VIRTA}

Leena Virta is a researcher who focuses on investigating the diversity of marine diatom communities and how it affects ecosystem functioning. *leena.virta@helsinki.fi

\section{ALF NORKKO}

Alf Norkko is a marine ecologist who works on seafloor environments. His research focuses on understanding how animals and plants influence the way marine ecosystems function. 